\section{Buckle-related complications following surgical repair of retinal dialysis}

\begin{abstract}
Aim To describe buckle-related complications following surgical repair of retinal dialysis.
\end{abstract}

Methods A retrospective study of 28 consecutive cryobuckle procedures for retinal detachments secondary to retinal dialysis is reported, with particular attention directed towards postoperative complications relating to the buckle. Stata 8 statistical software and Fisher's exact test were used to analyse the data.

Results Of the 28 cases, anatomic success was achieved with a single procedure in 26 cases $(\mathbf{9 2 . 9 \%})$. Postoperative complications were seen in 20 cases $(71.4 \%)$, with complications attributable to the buckle noted in 19 (67.9\%). Buckle-related complications included exposure $(7 ; 25 \%)$, strabismus $(5 ; 17.9 \%)$, and infection $(3 ; 10.7 \%)$. Surgical removal of the buckle was indicated in 13 cases $(46.4 \%)$, typically within the first 6 postoperative months. Of these, the retina remained flat following removal of buckle in 12 cases $(\mathbf{9 2 . 3 \%})$, whereas the retina redetached in one case $(7.7 \%)$. Conclusion Cryotherapy with explant is an effective primary procedure for the surgical repair of retinal detachment secondary to retinal dialysis. However, there is a high rate of postoperative complications relating to the buckle following this surgical approach, although the buckle can be safely removed without compromising the anatomic success of the primary surgery in the vast majority of cases.

Eye (2008) 22, 485-490; doi:10.1038/sj.eye.6702665; published online 1 December 2006

Keywords: retinal dialysis; complications; buckle; squint
M James, M O'Doherty and S Beatty

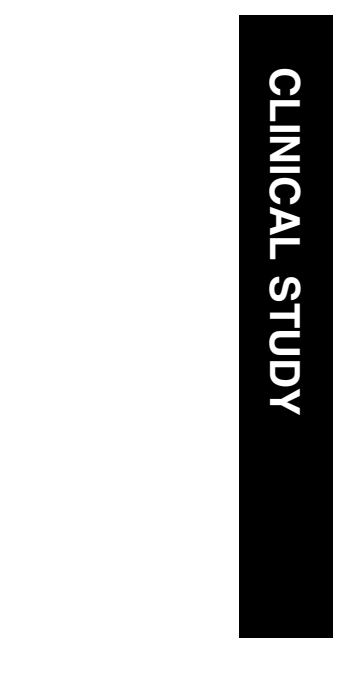

tissue from its origin at the ora serrata. ${ }^{1}$ Most, if not all, retinal dialyses follow trauma, and often present months to years after the causative insult. $^{1-4}$

The typical management of a retinal dialysis is a cryobuckle procedure. However, a buckle for this pathology is always circumferential and apposed to the ora serrata, and is typically secured with the intent of giving rise to a particularly deep indent, thus resulting in unique complications relating to the insertion of the extraocular muscles.

In this paper, we report on the functional and anatomic results of 28 cases of retinal dialysis repair over a 4-year period, and describe the complications relating to the buckle. To our knowledge, this article represents the first report that is primarily concerned with buckle-related complications associated with repair of retinal detachments secondary to retinal dialysis.

\section{Materials and methods}

All patients who underwent surgical repair of retinal detachment secondary to retinal dialysis in Waterford Regional Hospital between September 2001 and August 2005, inclusive, were identified from the theatre logbooks, and their medical case notes were retrieved. Data were recorded retrospectively for each subject, and was classed as demographic, preoperative, intraoperative, and postoperative.

Preoperative data included: age, sex, eye involved, prior ocular surgery (if any), method of referral, symptoms, visual acuity, nature of trauma (if any), duration of the detachment at presentation, macular status (on or off), location of dialysis, associated ocular pathology,
Department of Ophthalmology, Waterford Regional Hospital, Waterford, Ireland

Correspondence: M James,

Department of Ophthalmology, Waterford Regional Hospital, Waterford, Ireland Tel: + 35351848000 ; Fax: + 35351842128 . E-mail: drmjames@ hotmail.com

Received: 6 August 2006 Accepted in revised form: 13 October 2006 Published online: 1 December 2006

The authors have no financial or proprietary interests connected with this study, and no funding was involved 
presence or absence of proliferative vitreoretinopathy; and timing and nature of primary procedure. In patients for whom there was no clear history of trauma documented in the medical records, the patient was contacted by phone to obtain a more detailed history of any trauma that may have contributed to the condition.

Intraoperative data included the type and extent of buckle used, the extraocular muscles involved with the buckle, number and type of sutures used to secure buckle, type of anaesthesia; and any intraoperative complications.

Postoperative details included duration of follow-up, complications, additional surgical procedures, final visual outcome, whether or not the procedure was anatomically successful; and timing and reason for failure.

With respect to complications significant enough to warrant buckle removal, Stata 8 statistical software was used to analyse the data, and to estimate relative risk of buckle-related complications with respect to the type of explant used and with respect to the type of procedure performed. Fisher's exact test was used to determine whether any observed differences were significant.

\section{Results}

One hundred and sixty patients (165 eyes) underwent surgery for repair of a primary rhegmatogenous retinal detachment during the study period (see Table 1). Of these, 28 patients $(17 \%)$ underwent surgery for retinal detachment secondary to retinal dialysis. There were no cases of bilateral retinal dialysis. The mean $( \pm S D)$ age of the patients was $30.7( \pm 15.5)$ years, with a range of $6-63$ years. The male- to -female ratio was 4.6:1 (23 males and five females), and a definite history of blunt ocular trauma was given in 19 (67.9\%) cases (Table 2). The average $( \pm$ SD) duration of follow-up was $18.3( \pm 11.8)$ months.

Almost all primary procedures were performed by one consultant ophthalmic surgeon with a special interest in vitreo-retinal surgery $(23 ; 82.1 \%)$, and the remainder $(5 ; 17.9 \%)$ by a surgeon under his direct supervision. The majority of the dialyses were located inferotemporally (22 eyes; $78.6 \%)$, whereas three $(10.7 \%)$, two $(7.1 \%)$, and one $(3.6 \%)$ were located superotemporally, superonasally, and inferonasally, respectively.

The primary procedure consisted of localization of the dialysis, followed by cryotherapy to its posterior edge, using indirect ophthalmoscopy. Then a buckle was sutured to the sclera with 5/0 ethibond, varying in number from two to 10 , thus representing a mean $( \pm S D)$ of $1.26( \pm 0.36)$ sutures per clock hour. External drainage
Table 1 Clinical characteristics, surgical details, and anatomic and visual outcomes following retinal reattachment surgery in 165 cases attending the Department of Ophthalmology at Waterford Regional Hospital between September 2001 and August 2005, inclusive

\begin{tabular}{|c|c|c|}
\hline & Frequency & Percentage \\
\hline \multicolumn{3}{|l|}{ Break type } \\
\hline Horseshoe tear & 52 & 31.5 \\
\hline Retinal hole & 50 & 30.3 \\
\hline Mixed holes and tears & 21 & 12.7 \\
\hline Dialysis & 28 & 17.0 \\
\hline Giant tears & 5 & 3.0 \\
\hline Combined schisis & 4 & 2.4 \\
\hline No hole found & 5 & 3.0 \\
\hline \multicolumn{3}{|l|}{ Primary surgery } \\
\hline Vitrectomy & 80 & 48.5 \\
\hline Cryobuckle & 55 & 33.3 \\
\hline Combined vitrectomy and buckle & 30 & 18.2 \\
\hline \multicolumn{3}{|l|}{ Anaesthetic } \\
\hline General anaesthesia & 145 & 87.9 \\
\hline Local anaesthesia & 20 & 12.1 \\
\hline \multicolumn{3}{|l|}{ Reattachment rates } \\
\hline Primary success ${ }^{\mathrm{a}}$ & 137 & 83.0 \\
\hline Final success & 158 & 95.8 \\
\hline \multicolumn{3}{|l|}{ Visual outcome } \\
\hline $\begin{array}{l}\text { Improvement in Snellen visual } \\
\text { acuity of } 2 \text { or more lines }\end{array}$ & 64 & 38.8 \\
\hline $\begin{array}{l}\text { Snellen visual acuity of } 6 / 12 \text { or } \\
\text { better postoperatively }\end{array}$ & 68 & 41.2 \\
\hline \multicolumn{3}{|l|}{ Complication rate } \\
\hline $\begin{array}{l}\text { Cases where one or more } \\
\text { complications were encountered }\end{array}$ & 111 & 67.3 \\
\hline Buckle-related complications & 27 & 16.4 \\
\hline
\end{tabular}

${ }^{a}$ The primary success rate of cryobuckle procedures, excluding cases of retinal dialysis, was $23 / 27(85.2 \%)$.

was performed in six $(21.4 \%)$ cases and paracentesis performed in five $(17.9 \%)$ cases.

Details germane to the buckle type, number of sutures used, extent of retinal dialysis, and postoperative complications are given in Table 3. The most commonly used buckle type was a $5-\mathrm{mm}$ sponge $(21 ; 75 \%)$, whereas the remaining cases involved the use of a 3-mm sponge (4; $14.3 \%), 4 \times 12 \mathrm{~mm}$ sponge $(1 ; 3.6 \%), 277$ buckle $(1 ; 3.6 \%)$, or 279 buckle $(1 ; 3.6 \%)$.

Reattachment of the retina, defined as a retina which was anatomically attached at 3 months postoperatively, ${ }^{5}$ was achieved with a single procedure in $26(92.9 \%)$ cases. However, there was one late failure of retinal dialysis repair in a patient where the retina was confirmed to be flat 2 years postoperatively. In this case, the patient was 13 years old, and presented 34 months after the initial retinal reattachment procedure with an extruding buckle. 
She had a 3-month history of mucopurulent discharge from the operated eye, but repeatedly refused to attend the ophthalmology department sooner for psychosocial

Table 2 Details of causative trauma, where known, in cases of retinal dialysis

\begin{tabular}{lcr}
\hline Form & $N$ & $\%$ \\
\hline Hurling-related & 6 & 21.4 \\
Football & 2 & 7.1 \\
Elastic rope & 2 & 7.1 \\
Basketball & 1 & 3.6 \\
Rubber ball & 1 & 3.6 \\
Golfball & 1 & 3.6 \\
Fall & 1 & 3.6 \\
Kick from horse & 1 & 3.6 \\
Stone & 1 & 3.6 \\
Fist & 1 & 3.6 \\
Firework & 1 & 3.6 \\
Road traffic accident & 1 & 3.6 \\
\hline
\end{tabular}

reasons. Fundoscopy revealed recurrence of retinal detachment with proliferative vitreoretinopathy. During removal of the buckle, full-thickness scleral necrosis was noted at the site of the buckle, and the surgeon elected to leave the conjunctiva open and to treat with systemic antibiotics. One week later, this patient underwent resuturing of the scleral defect, vitrectomy, encirclement, and endolaser, and this latter procedure was successful.

The macula was attached and detached at presentation in $21(75 \%)$ and seven (25\%) eyes, respectively. At final follow-up, an improvement in two or more Snellen lines from presenting acuity was seen in $10(35.7 \%)$ eyes, and $16(57.1 \%)$ of the operated eyes exhibited no change in vision, whereas a deterioration of two or more Snellen lines was seen in two $(7.1 \%)$ eyes. A final best-corrected visual acuity (BCVA) of $6 / 12$ or better was achieved in $18(64.3 \%)$ eyes, and $10(35.7 \%)$ achieved a BCVA of $6 / 6$ or better in the operated eye.

Table 3 Clinical, surgical ${ }^{\text {a }}$, and postoperative details of 28 cases of retinal detachment secondary to retinal dialysis

\begin{tabular}{|c|c|c|c|c|c|c|}
\hline $\begin{array}{l}\text { Patient } \\
\text { no. }\end{array}$ & $\begin{array}{l}\text { Location of } \\
\text { retinal dialysis }\end{array}$ & $\begin{array}{l}\text { Buckle size } \\
\text { (mm) and type }\end{array}$ & $\begin{array}{l}\text { Number of } \\
\text { sutures }^{\mathrm{b}}\end{array}$ & $\begin{array}{l}\text { Extraocular } \\
\text { muscles involved } \\
\text { by buckle }\end{array}$ & $\begin{array}{c}\text { Extent of } \\
\text { buckle } \\
\text { (in clock hours) }\end{array}$ & $\begin{array}{l}\text { Postoperative } \\
\text { complications }\end{array}$ \\
\hline 1 & Inferotemporal & 3 & 3 & IR, LR, MR & 6 & Nil \\
\hline 2 & Inferotemporal & 5 & Unknown & IR, LR & 3 & Nil \\
\hline 3 & Inferotemporal & 5 & 8 & IR, LR, MR & 6 & Diplopia, pain, pigmentary maculopathy \\
\hline 4 & Inferotemporal & 5 & Unknown & IR, LR & 3 & Diplopia, epiretinal membrane \\
\hline 5 & Inferotemporal & 3 & 2 & IR & 2 & $\begin{array}{l}\text { Buckle exposure, central serous } \\
\text { chorioretinopathy }\end{array}$ \\
\hline 6 & Inferotemporal & 5 & 3 & IR & 2 & Pain \\
\hline 7 & Inferotemporal & 5 & 3 & IR, LR & 4 & Pain \\
\hline 8 & Inferotemporal & 5 & 6 & IR, LR & 5 & Pain, redness \\
\hline 9 & Inferotemporal & 5 & 5 & IR, LR & 5 & Epiretinal membrane \\
\hline 10 & Superotemporal & 5 & 6 & LR, SR & 4 & Pain, astigmatism \\
\hline 11 & Inferotemporal & 5 & 3 & IR & 2 & Nil \\
\hline 12 & Superotemporal & 5 & Unknown & LR, SR & 3 & Diplopia, buckle-related abscess \\
\hline 13 & Superotemporal & 3 & 3 & LR, SR & 3 & $\begin{array}{l}\text { Buckle exposure, buckle-related infection, } \\
\text { scleral necrosis, proliferative vitreoretinopathy }\end{array}$ \\
\hline 14 & Inferonasal & 279 buckle & 2 & IR, MR & 3 & Buckle exposure \\
\hline 15 & Inferotemporal & 3 & Unknown & IR, LR & 2 & Pain \\
\hline 16 & Superonasal & 5 & 5 & MR, SR & 3 & Pain, conjunctival retraction \\
\hline 17 & Inferotemporal & 5 & 3 & IR, LR & 3 & Nil \\
\hline 18 & Inferotemporal & 5 & 5 & IR, LR & 3 & Diplopia, buckle exposure \\
\hline 19 & Inferotemporal & $4 \times 12$ & 8 & IR, LR, MR & 6 & Nil \\
\hline 20 & Inferoremporal & 5 & 4 & IR, LR & 3 & Nil \\
\hline 21 & Inferotemporal & 5 & Unknown & IR, LR & 2 & Pain, raised intraocular pressure \\
\hline 22 & Inferotemporal & 5 & 4 & IR, LR & 3 & Diplopia \\
\hline 23 & Inferotemporal & 5 & 4 & IR & 2 & Buckle exposure, raised intraocular pressure \\
\hline 24 & Superonasal & 277 buckle & 3 & MR, SR & 3 & $\begin{array}{l}\text { Buckle exposure, conjunctival retraction, } \\
\text { buckle-related infection }\end{array}$ \\
\hline 25 & Inferotemporal & 5 & 5 & IR, LR & 5 & Conjunctival retraction \\
\hline 26 & Inferotemporal & 5 & 3 & IR & 2 & Buckle exposure, pain \\
\hline 27 & Inferotemporal & 5 & 5 & IR, LR & 3 & Nil \\
\hline 28 & Inferotemporal & 5 & 10 & IR, LR, MR & 7 & Nil \\
\hline
\end{tabular}

IR, inferior rectus; LR, lateral rectus; MR, medial rectus; SR, superior rectus.

aAll procedures were carried out under general anaesthetic, with cryotherapy to the posterior edge of the dialysis, followed by suturing of the buckle to the sclera.

b5/0 ethibond was used to suture the explant to the sclera in all cases. 
Table 4 Postoperative complications following surgical repair of retinal dialysis

\begin{tabular}{llc}
\hline & $N$ & $\%$ \\
\hline Buckle exposure & 7 & 25.0 \\
Diplopia and/or strabismus & 5 & 17.9 \\
Buckle-related infection & 3 & 10.7 \\
Epiretinal membrane & 3 & 10.7 \\
Conjunctival retraction & 3 & 10.7 \\
Raised intraocular pressure $^{\mathrm{a}}$ & 2 & 7.1 \\
Scleral necrosis & 1 & 3.6 \\
Eye redness & 1 & 3.6 \\
Astigmatism & 1 & 3.6 \\
Proliferative vitreoretinopathy & 1 & 3.6 \\
\hline
\end{tabular}

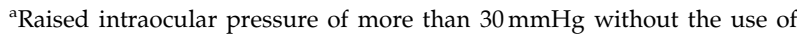
ocular hypotensive agents.

Intraoperative or postoperative complications were encountered in 21 cases $(75 \%)$, with some patients (13; $46.4 \%)$ experiencing more than one complication. Intraoperative complications included raised intraocular pressure (four; $14.3 \%$ ), scleral perforation with suture (one; $3.6 \%$ ), and vitreous haemorrhage (one; 3.6\%).

Buckle-related complications were seen in 19 (67.9\%) cases, and were represented by symptoms of pain (nine; $32.1 \%$ ), diplopia (five; $17.9 \%$ ), and redness (one; $3.6 \%$ ). Signs of buckle-related complications included exposure of explant (seven; 25\%), buckle-related infection (three; 10.7\%), conjunctival retraction (three; 10.7\%), astigmatism (one; $3.6 \%$ ), and scleral necrosis (one; $3.6 \%$ ). Two $(66.6 \%)$ of the three cases where infection was encountered were associated with exposure of the explant. Buckle-related complications occurred in 14 $(66.6 \%)$ of the 21 cases where a 5-mm buckle was used, and in five of the seven cases $(71.4 \%)$ where a buckle other than a 5 -mm sponge was used (3-mm sponge (3; 75\%); 277 buckle (1; 100\%); 279 buckle (1; 100\%)). Other postoperative complications included epiretinal membrane formation (three; $10.7 \%$ ) and proliferative vitreoretinopathy (one; $3.6 \%$ ) (see Table 4).

Removal of the buckle was clinically indicated in 13 (46.4\%) cases, and the majority of these (nine; $69.2 \%$ ) were removed within the first 6 postoperative months. Of these 13 cases, a 5-mm sponge was used in 10 (76.9\%), whereas a buckle other than a 5 -mm sponge was used in three $(23.1 \%)$. Supplementary prophylactic indirect laser was deemed necessary and performed in four (30.8\%) eyes before removal of the explant. This rate of buckle removal in cases of retinal dialysis is significantly greater than that encountered with cryobuckle procedures for retinal detachments not secondary to retinal dialysis in our unit over the same period, with five of 27 (18.5\%) buckles requiring removal in nonretinal dialysis cases $(P=0.044$, risk ratio $(\mathrm{RR}) 2.51,95 \% \mathrm{CI}: 1.03-6.08)$. Of
Table 5 Secondary surgical procedures following primary repair of retinal detachments secondary to retinal dialysis

\begin{tabular}{lcc}
\hline Procedure & No. of cases & $\%$ \\
\hline Buckle removal & 13 & 46.4 \\
Supplemental retinopexy & 7 & 25 \\
Resuturing of conjunctiva & 4 & 14.3 \\
Buckle trimming & 3 & 10.7 \\
Repeat reattachment surgery & 3 & 10.7 \\
Squint surgery & 1 & 3.6 \\
\hline
\end{tabular}

note, none of these 27 cases involved the use of a $5-\mathrm{mm}$ sponge.

The most common indication for removal of the buckle following dialysis repair was persistent diplopia (five; $38.5 \%$ ), whereas the others were removed because of persistent exposure of the explant (four; $30.8 \%$ ), ocular pain (three; $23.1 \%$ ), and failure of primary reattachment surgery (one; $7.7 \%$ ), the buckle in the latter case being replaced during the subsequent secondary reattachment procedure. A summary of other surgical interventions required beyond the primary retinal reattachment surgery is given in Table 5 .

Of the 21 retinal dialysis cases where a 5-mm buckle was used, a complication severe enough to warrant buckle removal was encountered in $10(47.6 \%)$ cases, which is higher than the aforementioned incidence in cases of retinal detachments not secondary to retinal dialysis (five per $27 ; 18.5 \%$ ), but the difference was not statistically significant $(P=0.058, \mathrm{RR} 2.57,95 \%$ CI: $1.04-$ 6.39). When we restrict our analysis to retinal dialysis cases, we found that there was only a slightly increased risk of buckle removal in cases where a $5-\mathrm{mm}$ sponge was used (10 of 21 , or $47.6 \%$ ), compared with cases in which a buckle of a different size was used (three of seven, or $42.9 \%)$, and that this was not statistically significant $(P=0.999, \mathrm{RR} 1.11,95 \%$ CI: 0.42-2.92).

The average duration of follow-up after buckle removal was 11.1 months, with $10(76.9 \%)$ of the 13 cases having at least 6 months follow-up. Of the cases where the buckle was removed, the retina redetached in one patient $(7.7 \%)$. Of note, this was a case in which the primary reattachment procedure was complicated by scleral perforation during suture placement, with a fresh retinal detachment, and subretinal and vitreous haemorrhage, seen on the first postoperative day, and which required repeat reattachment surgery before developing exposure of the explant 2 months later. In this case, a loose and obviously extruding explant was removed at the slit lamp in the outpatient department 8 weeks after the primary surgery, and the retina redetached within the following 3 weeks. Subsequently, this patient underwent vitrectomy, encirclement, and cryotherapy, and this latter procedure was 
successful, with an ultimate best-corrected final visual acuity of $6 / 24$.

\section{Discussion}

A retinal dialysis is a tear in the retina, the anterior edge of which is at the ora serrata and the posterior edge of which is attached to the vitreous base. ${ }^{1-3,6}$ Although sometimes difficult to distinguish from a giant retinal tear, there are several notable differences, including the fact that a posterior vitreous detachment is invariably associated with a giant retinal tear, but is rarely (if ever) seen in association with a retinal dialysis, as well as the finding that the vitreous base is attached to the anterior edge of the retina or ciliary epithelium in eyes with giant retinal tears. ${ }^{2,7}$ Typically, retinal dialysis accounts for $4-10 \%$ of all rhegmatogenous retinal detachments, ${ }^{2-5,8,9}$ but accounted for $17 \%$ of rhegmatogenous retinal detachments in our unit. The high incidence of retinal dialysis in the south-east of Ireland is attributable, at least in part, to the popular regional sport known as hurling. ${ }^{10}$ Indeed, $21.4 \%$ of retinal dialyses reported here were secondary to hurling-related ocular injury, and this was by far the most commonly cited cause of dialysis in this study.

The typical treatment for retinal dialysis involves cryotherapy to its posterior edge and placement of a circumferential buckle in an attempt to close the break. Unlike other buckling procedures, the explant used in the treatment of a retinal dialysis is always circumferential, and is placed at the ora serrata. Also, and in order to ensure an indent sufficiently deep to close a retinal dialysis, the surgeon typically endeavours to place very tight sutures for buckle placement.

The primary success rate of retinal reattachment in this study was high at $92.9 \%$, with final retinal reattachment achieved in $100 \%$. The deep indent created by securing a 5 -mm sponge with very tight sutures may play a role in sealing the dialysis more effectively, thereby leading to a greater success rate following primary reattachment surgery for retinal detachments secondary to retinal dialysis. Indeed, this high rate of success has been noted in previous studies $(93-100 \%) .^{2-4,11}$

However, there was a high incidence of buckle-related complications $(70.8 \%)$. One of the most common complications of any buckling procedure is exposure of the explant, with a consequentially increased risk of infection. In our study, buckle extrusion was encountered in seven $(25 \%)$ cases, and two $(28.6 \%)$ of these were associated with infection. Fortunately, we determined the overall incidence of infection to be low at $10.7 \%$, but higher than that found in other studies, $1.5-5.6 \% .{ }^{12-16}$ An explant-associated abscess responds poorly to antibiotics and represents an indication for removal of the offending buckle. ${ }^{13}$ Of note, in our study, two $(66.7 \%)$ of the three cases of buckle-related infection were identified only during removal of the buckle, revealing the abscesses beneath them.

Buckle-related complications severe enough to warrant removal of the explant occurred in $13(46.4 \%)$ of the 28 retinal dialysis cases. The most common indication for removal was persistent diplopia (38.5\%). This high incidence of clinical indications for removal of explants is significantly greater than that seen following cryobuckle procedures for retinal detachments not secondary to retinal dialysis (five of 27 , or $18.5 \%$ ) within our unit over the same period. One possible explanation for this finding may rest on the fact that a large 5 -mm sponge sutured to the ora serata gives rise to a higher rate of symptomatic complications, including diplopia, exposure of explant and ocular pain. However, it should be noted that the risk of buckle-related complications warranting removal following surgical repair of retinal dialysis was high for all forms of retinal dialysis surgery, irrespective of the type of buckle used. There is a much lower incidence of buckle removal reported in the literature in cases of retinal detachment surgery not limited to retinal dialysis cases $(1.3-24.4 \%){ }^{13,14,17-20}$ however, reports of surgical repair of retinal dialysis have primarily focused on visual and anatomical outcomes, and have failed to report or discuss buckle-related complications following this procedure. ${ }^{1-4,6-9,11}$ In other words, it is difficult for us to make any meaningful comment on our high rate of buckle-related complications following surgical repair of retinal dialysis.

Although removal of a scleral buckle can often be accomplished without much surgical difficulty, there is a risk of retinal redetachment, with reports varying from 3.2 to $34 \% .^{13,16-19,21-23}$ In this study, there was a low rate of retinal redetachment following removal of buckle $(7.7 \%)$, and, as mentioned previously, this case was remarkable owing to its complicated primary reattachment surgery, with globe perforation following suture placement. Also, as the buckle was obviously extruding in this particular case to such a degree that it could be safely and painlessly removed at the slit lamp, it is doubtful that this explant was creating an indent sufficient to contribute to a successful surgical outcome, or that its removal actually contributed to retinal redetachment. Cases were followed up for an average of 10.6 months following buckle removal, with $76.9 \%$ of cases having at least 6 months follow-up. It has been suggested that 6 months follow-up is adequate to identify cases of retinal detachment following buckle removal, as most cases that redetach will do so during this period, ${ }^{21,22}$ with the highest rate of redetachment occurring within the first 30 days. ${ }^{21}$ 
Risk of retinal redetachment following removal of a scleral explant is reportedly increased in the following instances: relatively short interval between the primary retinal detachment repair and removal of the buckle; ${ }^{22}$ the presence of retinal tears, as opposed to holes; ${ }^{22}$ if there are no breaks identified at the time of the primary reattachment surgery; ${ }^{17}$ the presence of vitreous traction at the time of the initial retinal detachment surgery; ${ }^{21,22}$ and greater extent of the original retinal detachment. ${ }^{21}$ It is possible that retinal dialysis repair is unlike other types of retinal detachment surgery, with uncomplicated cases having a much lower rate of redetachment following buckle removal.

In conclusion, there is a high rate of buckle-related complications following surgical repair of retinal detachment secondary to retinal dialysis. However, the buckle can be safely removed in the majority of cases, with or without supplementary laser retinopexy. It is possible that the use of a smaller explant may result in a lower incidence of postoperative buckle-related complications, but that a consequentially less substantial indent associated with the use of a smaller buckle may compromise the surgical success rate of primary reattachment surgery for retinal dialysis repair.

\section{References}

1 Zion VM, Burton TC. Retinal dialysis. Arch Ophthalmol 1980; 98: 1971-1974.

2 Hagler WS. Retinal dialysis: a statistical and genetic study to determine pathogenic factors. Trans Am Ophthalmol Soc 1980; 78: 686-733.

3 Vote BJ, Caswell AG. Retinal dialysis: are we missing diagnostic opportunities? Eye 2004; 18: 709-713.

4 Ross WH. Traumatic retinal dialysis. Arch Ophthalmol 1981; 99: 1371-1374.

5 Thompson JA, Snead MP, Billington BM, Barrie T, Thompson JR, Sparrow JM. National audit of the outcome of primary surgery for rhegmatogenous retinal detachment. I. Sample and methods. Eye 2002; 16: 766-770.

6 Scott JD. Retinal dialysis. Trans Ophthalmol Soc UK 1977; 97(1): 33-35.
7 Hamrick KE, Helgeson MK. Retinal dialysis. Optom clin 1992; 2(3): 93-112.

8 Kennedy CJ, Parker CE, McAllister IL. Retinal detachment caused by retinal dialysis. Aust N Z J Ophthalmol 1997; 25(1): 25-30.

9 Chignell AH. Retinal dialysis. Br J Ophthalmol 1973; 57: 572-577.

10 Flynn TH, Fennessy K, Horgan N, Walsh B, O' Connell E, Cleary P et al. Ocular injury in hurling. Br J Sports Med 2005; 39(8): 493-496.

11 Kinyoun JL, Knobloch WH. Idiopathic retinal dialysis. Retina 1984; 4: 9-14.

12 Hadden OB. Infection after retinal detachment surgery. Aust N Z J Ophthalmol 1986; 14(1): 69-73.

13 Ulrich RA, Burton TC. Infections following scleral buckling procedures. Arch Ophthalmol 1974; 92: 213-215.

14 Flindall RJ, Norton EW, Curtin VT, Gass JD. Reduction of extrusion and infection following episcleral silicone implants and cryopexy in retinal detachment surgery. Am J Ophthalmol 1971; 71: 835-837.

15 Smiddy WE, Miller D, Flynn Jr HW. Scleral buckle removal following retinal reattachment surgery: clinical and microbiologic aspects. Ophthalmic Surg 1993; 24(7): 440-445.

16 Hahn YS, Lincoff A, Lincoff H, Kreissig I. Infection after sponge implantation for scleral buckling. Am J Ophthalmol 1979; 87(2): 180-185.

17 Deutsch J, Aggarwal RK, Eagling EM. Removal of scleral explant elements: a 10 year retrospective study. Eye 1992; 6: 570-573.

18 Hilton GF, Wallyn RH. The removal of scleral buckles. Arch Ophthalmol 1978; 96(11): 2061-2063.

19 Russo CE, Ruiz RS. Silicone sponge rejection: early and late complications in retinal detachment surgery. Arch Ophthalmol 1971; 85: 647-650.

20 Roldan-Pallares M, del Castillo Sanz JL, Awal-El Susi S, Refojo MF. Long-term complications of silicone and hydrogel explants in retinal reattachment surgery. Arch Ophthalmol 1999; 117(2): 197-201.

21 Lindsey PS, Pierce LH, Welch RB. Removal of scleral buckling elements. Causes and complications. Arch Ophthalmol 1983; 101(4): 570-573.

22 Schwartz PL, Pruett RC. Factors influencing retinal redetachment after removal of buckling elements. Arch Ophthalmol 1977; 95(5): 804-807.

23 Kearney JJ, Lahey JM, Borirakchanyavat S, Schwartz DM, Wilson D, Tanaka SC et al. Complications of hydrogel explants used in scleral buckling surgery. Am J Ophthalmol 2004; 137(1): 96-100. 